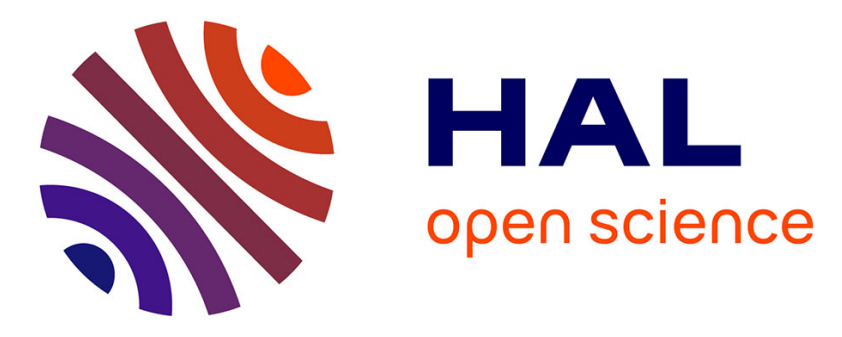

\title{
Protective effect of myostatin gene deletion on aging-related muscle metabolic decline
}

Béatrice Chabi, M. Pauly, J. Carillon, Gilles Carnac, François Bertrand Favier, Gilles Fouret, Béatrice Bonafos, Frankie Vanterpool, Barbara Vernus, Charles Coudray, et al.

\section{To cite this version:}

Béatrice Chabi, M. Pauly, J. Carillon, Gilles Carnac, François Bertrand Favier, et al.. Protective effect of myostatin gene deletion on aging-related muscle metabolic decline. Experimental Gerontology, 2016 , 78, pp.23 - 31. 10.1016/j.exger.2016.01.016 . hal-01804186

\section{HAL Id: hal-01804186 \\ https://hal.umontpellier.fr/hal-01804186}

Submitted on 2 Dec 2019

HAL is a multi-disciplinary open access archive for the deposit and dissemination of scientific research documents, whether they are published or not. The documents may come from teaching and research institutions in France or abroad, or from public or private research centers.
L'archive ouverte pluridisciplinaire HAL, est destinée au dépôt et à la diffusion de documents scientifiques de niveau recherche, publiés ou non, émanant des établissements d'enseignement et de recherche français ou étrangers, des laboratoires publics ou privés. 


\title{
Protective effect of myostatin gene deletion on aging-related muscle metabolic decline
}

\author{
B. Chabi, M. Pauly, J. Carillon, G. Carnac, F.B. Favier, G. Fouret, B. \\ Bonafos, F. Vanterpool, B. Vernus, C. Coudray, et al.
}

\section{- To cite this version:}

B. Chabi, M. Pauly, J. Carillon, G. Carnac, F.B. Favier, et al.. Protective effect of myostatin gene deletion on aging-related muscle metabolic decline. Experimental Gerontology, Elsevier, 2016, 78, pp.23 - 31. 10.1016/j.exger.2016.01.016 . hal-01804186

\section{HAL Id: hal-01804186 \\ https://hal.umontpellier.fr/hal-01804186}

Submitted on 2 Dec 2019

HAL is a multi-disciplinary open access archive for the deposit and dissemination of scientific research documents, whether they are published or not. The documents may come from teaching and research institutions in France or abroad, or from public or private research centers.
L'archive ouverte pluridisciplinaire HAL, est destinée au dépôt et à la diffusion de documents scientifiques de niveau recherche, publiés ou non, émanant des établissements d'enseignement et de recherche français ou étrangers, des laboratoires publics ou privés. 


\title{
Protective effect of myostatin gene deletion on aging-related muscle metabolic decline
}

\author{
B. Chabi ${ }^{a}$, M. Pauly ${ }^{a}$, J. Carillon ${ }^{b}$, G. Carnac ${ }^{c}$, F.B. Favier ${ }^{a}$, G. Fouret ${ }^{a}$, B. Bonafos ${ }^{\text {a }}$, F. Vanterpool ${ }^{\text {a }}$, B. Vernus ${ }^{\text {a }}$, \\ C. Coudray ${ }^{a}$, C. Feillet-Coudray ${ }^{a}$, A. Bonnieu ${ }^{a}$, D. Lacan ${ }^{b}$, C. Koechlin-Ramonatxo ${ }^{\mathrm{a}, *}$ \\ a INRA, UMR866 Dynamique Musculaire et Métabolisme, Université Montpellier, F-34060, Montpellier, France \\ bionov Sarl, Avignon, France \\ ' Inserm U1046, Université 'Montpellier, 34295 Montpellier, France
}

Keywords:

GDF-8 deletion

Respiratory control ratio

SODB

Running capacity

Antioxidant

\begin{abstract}
A B S T R A C T
While myostatin gene deletion is a promising therapy to fight muscle loss during aging, this approach induces also skeletal muscle metabolic changes such as mitochondrial deficits, redox alteration and increased fatigability. In the present study, we evaluated the effects of aging on these features in aged wild-type (WT) and mstn knockout (KO) mice. Moreover, to determine whether an enriched-antioxidant diet may be useful to prevent agerelated disorders, we orally administered to the two genotypes a melon concentrate rich in superoxide dismutase for 12 weeks. We reported that mitochondrial functional abnormalities persisted (decreased state 3 and 4 of respiration; $p<0.05$ ) in skeletal muscle from aged KO mice; however, differences with WT mice were attenuated at old age in line with reduced difference on running endurance between the two genotypes. Interestingly, we showed an increase in glutathione levels, associated with lower lipid peroxidation levels in KO muscle. Enriched antioxidant diet reduced the aging-related negative effects on maximal aerobic velocity and running limit time $(p<0.05)$ in both groups, with systemic adaptations on body weight. The redox status and the hypertrophic phenotype appeared to be beneficial to $\mathrm{KO}$ mice, mitigating the effect of aging on the skeletal muscle metabolic remodeling.
\end{abstract}

\section{Introduction}

Skeletal muscle represents the largest organ of human body. Its main functions are to provide movement and autonomy and to balance posture as well as to regulate the body temperature. Loss of skeletal muscle occurs as a consequence of several chronic diseases (cachexia) as well as normal aging (sarcopenia), and may play a role in reduced physical performance, falls, disability, and mortality for an increasing number of elderly patients (Fielding et al., 2011). Consequently, numerous potential therapeutic approaches are being considered and developed. One of the most promising approaches is inhibition of the myostatin signalling (McPherron et al., 1977; Matsakas, 2014; Rodriguez et al., 2014).

Myostatin (mstn), a member of the transforming growth factors superfamily, is a highly conserved negative regulator of skeletal muscle mass (McPherron et al., 1977). The induced or natural conditions leading to myostatin inactivation or inhibition result in an increased muscle mass and are considered as promising therapeutic approaches to prevent muscle wasting associated with numerous disorders such as myopathies (Hulmi et al., 2013; Amthor and Hoogaars, 2012), cancer (Busquets et al., 2012; Gallot et al., 2014),

\footnotetext{
* Corresponding author.

E-mail address: christelle.ramonatxo@umontpellier.fr (C. Koechlin-Ramonatxo).
}

or aging (Morissette et al., 2009; Collins-Hooper et al., 2014; Mendias et al., 2015). In addition to its role in skeletal muscle growth, myostatin has recently been reported to be significantly involved in the regulation of muscle metabolism. Indeed, early studies provided evidence at the cellular level that deletion of myostatin in glycolytic skeletal muscles led to loss of oxidative properties, with impaired activity of oxidative metabolism enzymes, a reduced capillary density, mitochondrial DNA depletion, and an uncoupled respiration in the intermyofibrillar mitochondria (Amthor et al., 2007; Lipina et al., 2010; Ploquin et al., 2012). This disturbance in oxidative metabolism and mitochondrial deficits is also associated with an alteration in redox homeostasis (Ploquin et al., 2012; Sriram et al., 2011) and increased muscle fatigability (Giannesini et al., 2013; Relizani et al., 2014; Mouisel et al., 2014). Notably, mstn-deficient fast-twitch skeletal muscles exhibit a significant decrease in lipid peroxidation levels together with a significant upregulation of the antioxidant glutathione system. By contrast, mitochondrial superoxide dismutase (MnSOD) and catalase activities are compromised with a reduction of up to $80 \%$ compared to control muscles (Ploquin et al., 2012). The mitochondrial deficit and the redox homeostasis alteration in skeletal muscle raise a number of questions. First, does mstn deletion alter mitochondrial yield and redox signaling in other organs with high oxidative potential such as the liver? 
Indeed, available data have not explored whether these metabolic features were exclusive to skeletal muscles. Second, are the metabolic features described in young mstn-deficient mice attenuated or worsened with aging? Numerous papers have assigned mitochondrial function and redox status as the primary (initially) or secondary (new vision) causes of age-related muscle disorders (Derbré et al., 2014). At subcellular level, aged muscle fibers display an increased level of mitochondrial abnormalities and susceptibility to apoptosis (Chabi et al., 2008). Aged mammalian and human populations exhibited higher muscle oxidative damage, as indicated by reduced glutathione levels and increased protein and DNA oxidation as well as lipid peroxidation (Marzani et al., 2005; Pansarasa et al., 1999). In this context, the consequences of mstn deletion on muscle redox status and mitochondrial metabolism in aged mice remain to be investigated. Despite the deficit in oxidative metabolism, the global reduced redox state in mstn-deficient skeletal muscle could be beneficial to counteract age-related oxidative stress. By contrast, the fast-twitch muscle phenotype observed in young mice with natural or constitutive deletion of mstn (Girgenrath et al., 2005) associated to the strong decrease in MnSOD activity reported in glycolytic muscles could be thus a disadvantage for "healthy aging." Indeed, decrease or lack of adaptation in antioxidant activities, such as MnSOD and GPx, has been reported in glycolytic muscles (Derbré et al., 2014). Finally, it would be interesting to study the effect of dietary antioxidant-enriched supplementation in aged mice with and without mstn deletion. An original way could be to supply antioxidant enzymes to the mice that have long-lasting effects due to their lower rate of exhaustion compared to mere metabolites, such as SODB, a melon concentrate particularly rich in SOD with reported beneficial antioxidant effects in several models with increased oxidative stress (Carillon et al., 2013).

Thus, the aim of this study is to identify the effect of aging on the regulation of mitochondrial function and redox status by constitutive mstn deletion, in glycolytic skeletal muscles and liver, and to determine whether an antioxidant diet may be useful to prevent age-related disorders. Here we demonstrated that mitochondrial function and redox signaling are specifically altered in skeletal muscle compared to liver in mstn-deficient mice. Beyond muscle hypertrophy, we showed that a reduced redox status persists in aged mstn KO muscle. Moreover, the metabolic differences between WT and KO mice tended to diminish with age, in particular, mitochondrial function. In this direction, the difference in running endurance between both groups of aged mice is also attenuated. In both genotypes, supplementation by an enriched antioxidant diet reduced the negative aging effects on running outcomes, associated with systemic adaptations as seen on the body weight measurements. The redox status and the hypertrophic phenotype appeared as beneficial adaptations in KO mice because it has attenuated the effect of aging on the skeletal muscle metabolic remodeling.

\section{Experimental procedures}

\subsection{Animals}

Twenty-month-old male mstn KO (aged KO, $n=16$ ) and wildtype male mice (aged WT, $n=17$ ) and 2-month-old male mstn KO (young KO, $n=10$ ) and wild-type male mice (young WT, $n=10$ ) were included in the study. Male mstn KO mice used in this study have been described previously (Grobet et al., 2003). WT and mstn KO mice were produced from homozygous matings, and genotypewas determined by PCR analysis of tail DNA.

Mice were fed ad libitum and kept under a 12:12-h light-dark cycle. The experimental protocols of this study were handled in strict accordance with European directives (86/609/CEE) and approved by the Ethical Committee of Region Languedoc Roussillon.

\subsection{Antioxidant supplementation}

SOD by Bionov (SODB, Avignon, France) is a melon (not Genetic Modified Organism) concentrate, particularly rich in SOD, resulting from a patented extraction process. For nutraceutical applications, SODB is coated with palm oil, by spray drying method, in order to preserve SOD activity from the digestive enzymes secreted above the small intestine. In this study, SODB contains $14 \mathrm{U}$ SOD/mg powder measured according to Zhou and Prognon (2006). Aged WT and mstn KO mice received the SOD-melon concentrate SODB, mixed with food, at the daily dose of $40 \mathrm{U}$ SOD for 3 months (aged WT + SODB; aged KO + SODB, $n=8$ in each group).

\subsection{Aerobic exercise tolerance and endurance capacity}

Young and aged mice were submitted to two running tests on a treadmill. Maximal aerobic velocity (MAV) was determined following a running test, where the speed was gradually increased by $2 \mathrm{~m} / \mathrm{min}$ from $10 \mathrm{~m} / \mathrm{min}$ until exhaustion. Exhaustion was defined when the mice were no longer able to maintain their normal running position and/or after 5 consecutive seconds in contact with the shock grid $(\leq 0.2 \mathrm{~mA})$ at the rear of the treadmill. Endurance capacity was determined via a submaximal running test where the speed starts at $10 \mathrm{~m} /$ min for the first $2 \mathrm{~min}$ and was set to $70 \%$ of MAV until exhaustion. The endurance limit time was recorded. Mice were killed $48 \mathrm{~h}$ after the last running test.

Same running tests were performed in blinded manner in aged mice with (aged WT + SODB; aged KO + SODB) and without (aged WT + placebo; aged KO + placebo) the antioxidant supplementation diet, before (at 20 months) and after (at 23 months) the nutritional treatment.

\subsection{Sampling}

At the end of the dietary supplementation, mice were weighed and euthanized by cervical dislocation. Liver, quadriceps, gastrocnemius, tibialis anterior (TA), and extensor digitorum longus (EDL) were removed, weighed, and either immediately placed into ice-cold buffer (100 mM KCl, 5 mM MgSO 4 , 5 mM EDTA, 50 mM Tris-HCl, pH 7.4) for mitochondrial isolation, or frozen in liquid nitrogen, and stored at $-80^{\circ} \mathrm{C}$ for enzymatic and protein analysis.

\subsection{Mitochondrial isolation and respiration}

Mixed muscles (quadriceps, gastrocnemius, and tibialis anterior) were freed from connective tissues, briefly minced, and homogenized with a Potter-Elvehjem homogenizer. Subsarcolemmal (SS) and intermyofibrillar (IMF) mitochondria were fractionated by differential centrifugation as described previously (Cogswell et al., 1993). Mitochondria were resuspended in $100 \mathrm{mM} \mathrm{KCl}, 10 \mathrm{mM}$ MOPS, pH 7.4. Mitochondrial protein content was determined using the Bradford assay, and the yield was expressed as mg of mitochondrial proteins per gram of muscle wet weight. SS and IMF mitochondrial oxygen consumption was measured using the high-resolution Oxygraph-2 k (OROBOROS Instruments, Innsbruck, Austria) as previously described (Ploquin et al., 2012). Resting rate (state 4 ) was evaluated in the presence of $2.5 \mathrm{mM}$ malate, $5 \mathrm{mM}$ glutamate, and $5 \mathrm{mM}$ succinate; ADP-stimulated rate (state 3 ) was determined after addition of $0.5 \mathrm{mM}$ ADP. The respiratory control ratio (RCR) was set as the ratio of oxygen consumption at state 3 over oxygen consumption at state 4 .

2.6. Mitochondrial respiratory complexes and citrate synthase activities in tissues

Mitochondrial activities were measured in gastrocnemius, and liver. Complex I activity was measured according to Cogswell et al. 
(1993): the method is based on measuring spectrophotometrically 2,6-dichloroindophenol reduction by electrons accepted from decylubiquinol, reduced after oxidation of NADH by complex I. Complex II (CII) and complex II + III (CII + CIII) activities were measured according to Rustin et al. (1994): succinate-ubiquinone reductase and succinate-cytochrome $c$ reductase activity were respectively determined spectrophotometrically. Cytochrome $c$ oxidase (COX) activity was measured according to Wharton et al. (1967): oxidation of reduced cytochrome $c$ is followed spectrophotometrically. For citrate synthase (CS), the activity of the enzyme is measured by following the color of 5-thio-2-nitrobenzoic acid, which is generated from 5,5'-dithiobis-2nitrobenzoic acid present in the reaction of citrate synthesis and caused by the deacetylation of acetyl-CoA (Ploquin et al., 2012).

\subsection{Determination of antioxidant activities}

Total and manganese superoxide dismutases (SOD and Mn-SOD) were measured according to the method of Marklund and Marklund (1974). Catalase activity was measured according to the method of Beers and Sizer (1952). Total glutathione (GSH) was measured according to the method of Griffith (1980). Glutathione peroxidase (GPX) was measured according to the method of Flohe and Gunzler (1984). Glutathione reductase (GRx) was measured according to the method of Carlberg and Mannervik (1985). Measurements were run in duplicate with a CV less than $15 \%$. Lipid peroxidation levels or thiobarbituric acid reactive substances (TBARS) were measured in tissue homogenates (gastrocnemius and soleus) as previously described (Ploquin et al., 2012).

\subsection{Immunoblotting}

Frozen EDL muscle samples were homogenized using an Ultra Turrax homogenizer in an ice-cold extraction buffer ( $20 \mathrm{mM}$ Tris, $\mathrm{pH} 7.4,150 \mathrm{mM} \mathrm{NaCl}, 1 \mathrm{mM}$ EDTA, $0.1 \%$ SDS, and 1\% Triton X-100). Protease and phosphatase inhibitors were added before extraction. Homogenates were sonicated and then centrifuged at $14,000 \mathrm{~g}$ for $15 \min$ at $4{ }^{\circ} \mathrm{C}$.

For protein expression, $50 \mu \mathrm{g}$ was separated on SDS-PAGE gel at the appropriate concentration of acrylamide and transferred onto nitrocellulose membrane. Total protein on the membrane was visualized by Ponceau red staining, and this was used to verify equal loading among the lanes. Blots were blocked $(1 \mathrm{~h})$ with $5 \%$ bovine serum albumin (BSA) in $1 \times$ Tris-buffered saline- $0.2 \%$ Tween 20 (TBST), followed by overnight incubation with antibodies directed toward rpS6, phosphor rpS6 (Ser235/236), 4EBP1, and phospho-4EBP1 (Thr37/46) (Cell Signaling Technology, Danvers, MA). After three 5-min washes at room temperature with TBST, blots were incubated at room temperature $(1 \mathrm{~h})$ with a secondary antibody conjugated with horseradish peroxidase. Blots were again subjected to three 5-min washes at room temperature with TBST, and antibody-bound proteins were revealed using the ECL reagent (Bio-Rad Life Science, Hercules, CA). Films were scanned and analyzed using Image J software. All blots were corrected for loading using Ponceau red staining.

For carbonyls protein immunodetection, $25 \mu \mathrm{g}$ of proteins was prepared according to the Millipore Oxyblot ${ }^{\mathrm{TM}}$ protein oxidation detection kit instructions (Millipore). Briefly, proteins extracts were derivatized with 2,4-dinitro phenyl hydrazine derivatization for $30 \mathrm{~min}$ and separated on $12 \%$ SDS/polyacrylamide gel. Total proteins were transferred onto nitrocellulose membrane and visualized by Ponceau red staining. After an overnight incubation with anti-4-dinitro phenylhydrazine antibody, antibody-bound proteins were revealed using the ECL reagent (Bio-Rad Life Science, Hercules, CA). Films were scanned and analyzed using Image J software. All blots were corrected for loading using Ponceau red staining.

\subsection{Statistical analysis}

All data are presented as the mean \pm SEM. A two-way analysis of variance (ANOVA) followed by Tukey's pairwise multiple comparison procedure was used to determine the effects of aging, genotype, or SODB supplementation. An unpaired $t$ test or a Mann-Whitney rank sum test when normality was not obtained was used to compare directly two groups. The significance level was set at 0.05 . The data were analysed using the statistical package Statview.

\section{Results}

\subsection{Skeletal muscle hypertrophy in aged KO mice}

Heart and liver weights were similar between WT and mstn KO mice groups and increased with age, together with the increase in body weight (Table 1). Mstn deletion has a main positive effect on absolute and relative muscle mass (Table 1). For example, TA weights of young and aged KO mice were heavier by $153 \%$ and $175 \%$ compared to agematched WT mice. By contrast, aging had a negative effect on relative muscle mass in WT mice only (Table 1 ).

\subsection{Myostatin deletion did not alter mitochondrial activity and oxidative stress markers level in liver}

Citrate synthase and COX activities were decreased with aging in liver for both WT and KO mice (Supplemental Fig. 1). No significant difference was reported between the two genotypes. Regarding redox status, aging increased TBAR levels by $30 \%$ in both WT and KO animals, while MnSOD activity was neither altered by aging nor genotype.

3.3. Mitochondrial abnormalities due to mstn deletion were attenuated with aging in skeletal muscles

Mstn deletion resulted in a decreased CS activity in the gastrocnemius muscle of both young and aged groups ( $*^{* *} p<0.001$; Fig. 1 ). We next measured the activities of the mitochondrial electron transport chain (ETC) complexes and normalized for mitochondrial content with total CS activity. In young mice, a significant increase was observed for the complex II + III and COX activity in gastrocnemius muscle of mstn KO mice compared with WT mice $\left({ }^{*} p<0.05\right.$; Fig. 1). Aging induced a significant increase in complex I activity only in WT mice and reduced the complex II + III activity in both genotypes $\left({ }^{\S} p<0.01\right.$, Fig. 1 ). No significant aging effect was reported for complex II and COX activities.

Functions of SS and IMF mitochondria were only studied in aged mice groups (Fig. 2), as well as antioxidant muscle defense and oxidative stress markers (Fig. 2). Once again, mitochondrial depletion $(40 \%, p<0.01)$ was found in aged mstn KO mice for IMF subfractions compared with WT mice. By contrast, a significant higher SS mitochondrial yield was reported in the KO mice (Fig. 2). IMF and SS respiration were both altered in aged mstn KO mice compared to aged WT mice: aged KO mice exhibited a significantly lower basal oxygen consumption measured at state 4 and at state 3 (Fig. 2) compared to aged WT. Nevertheless, no significant alteration of the RCR was found in both mitochondrial subpopulations between the two aged genotypes.

\subsection{Reduced redox status due to mstn deletion is preserved with aging in skeletal muscles}

Antioxidant catalase and SOD enzyme activity measurement in gastrocnemius from aged mstn KO mice were significantly reduced. Notably, SODt and MnSOD activities were respectively decreased by $28 \%$ and up to $46 \%$ in aged mstn KO gastrocnemius muscles compared with aged WT (Fig. 2). The amount of total GSH was elevated 
Table 1

Aging effect on organs and skeletal muscle mass.

\begin{tabular}{|c|c|c|c|c|}
\hline \multirow[b]{2}{*}{ Weight } & \multicolumn{2}{|l|}{ WT } & \multicolumn{2}{|l|}{ КО } \\
\hline & Young $n=10$ & Aged $n=9$ & Young $n=10$ & Aged $n=9$ \\
\hline Body (g) & $29.3 \pm 1.5$ & $43.3 \pm 2.3^{\S \S \S}$ & $36.4 \pm 1.0^{* *}$ & $42.8 \pm 0.9^{\S \S}$ \\
\hline Heart (mg) & $169 \pm 12$ & $261 \pm 14^{\S \S \S}$ & $166 \pm 11$ & $247 \pm 15^{\S \S \S}$ \\
\hline Heart/BW (mg/g) & $5.8 \pm 0.5$ & $6.1 \pm 0.4$ & $4.7 \pm 0.3$ & $5.8 \pm 0.4$ \\
\hline Liver (mg) & $1417 \pm 132$ & $2207 \pm 144^{\S \S \S}$ & $1458 \pm 40$ & $1869 \pm 102^{\S \S \S}$ \\
\hline Liver/BW (mg/g) & $48.0 \pm 3.6$ & $51.0 \pm 2.4$ & $40.2 \pm 1.1^{* *}$ & $43.6 \pm 2.1^{* *}$ \\
\hline $\mathrm{TA}(\mathrm{mg})$ & $58.0 \pm 5.1$ & $57.3 \pm 3.5$ & $88.7 \pm 3.2^{* * *}$ & $100.3 \pm 9.1^{* * *}$ \\
\hline $\mathrm{TA} / \mathrm{BW}(\mathrm{mg} / \mathrm{g})$ & $2.0 \pm 0.2$ & $1.3 \pm 0.6^{\S}$ & $2.5 \pm 1.0^{*}$ & $2.3 \pm 0.2^{* * *}$ \\
\hline $\operatorname{EDL}(\mathrm{mg})$ & $10.7 \pm 1.3$ & $8.9 \pm 0.5$ & $17.8 \pm 1.0^{* * *}$ & $19.7 \pm 1.3^{* * *}$ \\
\hline EDL/BW (mg/g) & $0.35 \pm 0.03$ & $0.21 \pm 0.01^{\S \S \S}$ & $0.51 \pm 0.03^{* * *}$ & $0.46 \pm 0.03^{* * *}$ \\
\hline GAS (mg) & $156.5 \pm 7.9$ & $163.4 \pm 6.5$ & $254.8 \pm 4.0^{* * *}$ & $312.7 \pm 25.4^{* * *, \S \S \S}$ \\
\hline GAS/BW (mg/g) & $5.4 \pm 0.2$ & $3.8 \pm 0.06^{\S \S \S}$ & $7.3 \pm 0.1^{* * *}$ & $7.2 \pm 0.5^{* * * *}$ \\
\hline Soleus (mg) & $7.8 \pm 0.7$ & $7.7 \pm 0.7$ & $13.7 \pm 2.0^{* * * *}$ & $12.2 \pm 0.4^{* * * *}$ \\
\hline Soleus/BW (mg/g) & $0.27 \pm 0.03$ & $0.18 \pm 0.02^{\S \S \S}$ & $0.39 \pm 0.02^{* * * *}$ & $0.29 \pm 0.04^{* * *}, \S \S \S$ \\
\hline
\end{tabular}

Data are presented as mean \pm SEM. TA, tibialis anterior; EDL, extensor digital longus, GAS, gastrocnemius; BW, body weight.

$* p<0.05$ vs. WT.

** $p<0.01$ vs. WT.

*** $p<0.001$ vs. WT.

$\S p<0.05$ vs. young.

$\S \S p<0.01$ vs. young.

$\S \S \S p<0.001$ vs. young.

( $+41 \%)$ in aged mstn $\mathrm{KO}$ mice. The GPx activity was not altered by genotype (data not shown). Concerning skeletal muscle oxidation products, lipid peroxidation was significantly decreased in mstn KO gastrocnemius relative to WT $\left({ }^{* * *} p<0.001\right.$; Fig. 2 ). Protein oxidation assessed by the evaluation of thiol levels and carbonylation profile was not altered by mstn depletion (data not shown).
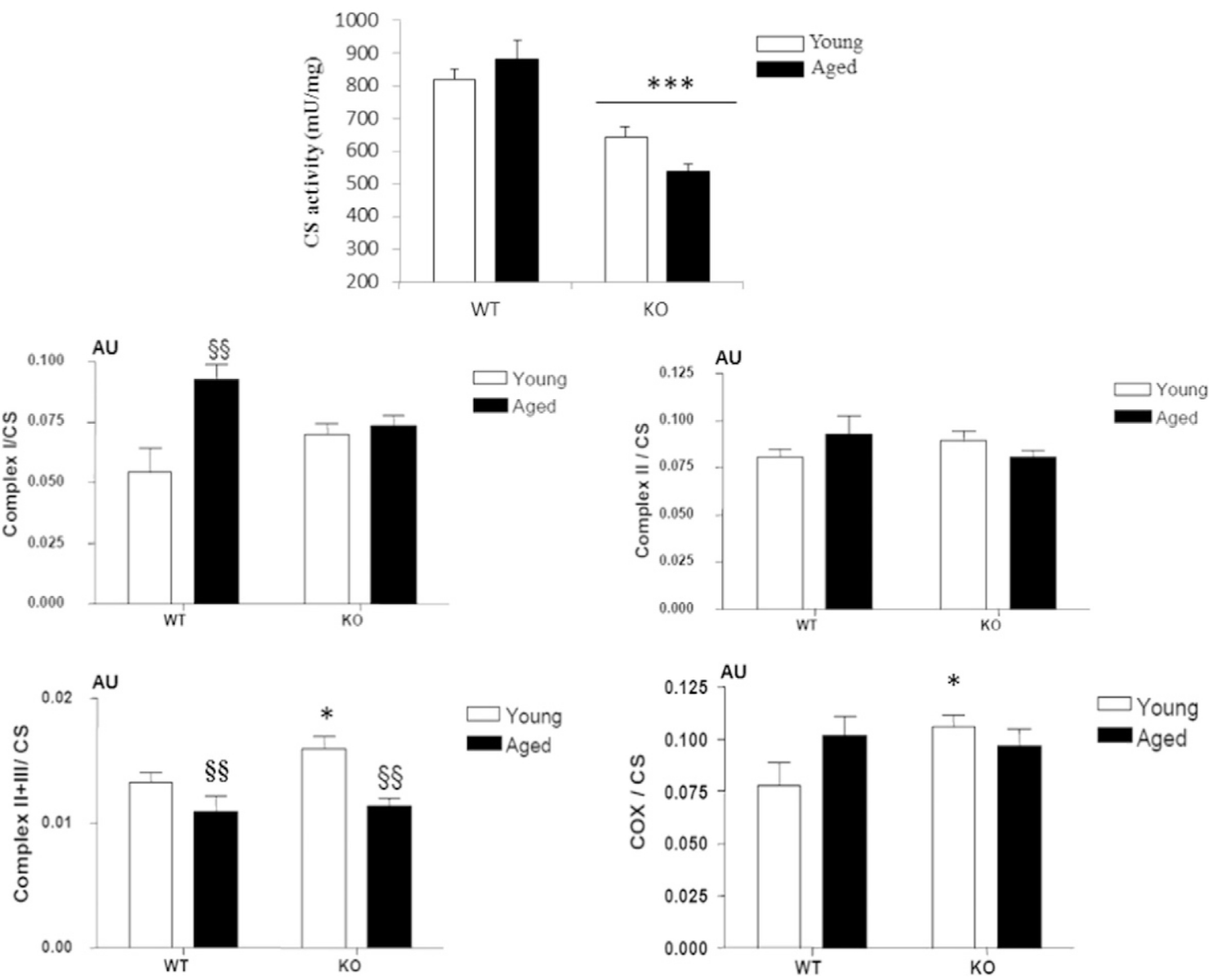

Fig. 1. Effect of aging and myostatin deletion on gastrocnemius citrate synthase and mitochondrial ETC complex activities. Enzymatic activities of CS and mitochondrial complexes in gastrocnemius muscle homogenates from young (open bars) and aged (filled bars) mice. Data are presented as mean \pm SEM; $n=9-10$ mice. CS, citrate synthase; COX, cytochrome $c$ oxidase; ${ }^{*} p<0.05$ and ${ }^{* * *} p<0.001$ vs. WT; ${ }^{\S} p<0.05$ and ${ }^{\S \S} p<0.01$ vs. young. $n=9-10$ in each group; AU, arbitrary units. 


\begin{tabular}{lcc} 
& AGED WT & AGED KO \\
\hline SS Mitochondria & $0.28 \pm 0.05$ & $0.51 \pm 0.06^{* * *}$ \\
Mitochondrial yield, $\mathrm{mg} / \mathrm{g}$ muscle & $2037 \pm 500$ & $852 \pm 154^{* * *}$ \\
Respiration State $4 \mathrm{pmol} \mathrm{O} 2 \cdot \mathrm{min}^{-1} \cdot \mathrm{mg}^{-1}$ & $5566 \pm 148$ & $2939 \pm 456^{*}$ \\
Respiration State $3 \mathrm{pmol} \mathrm{O}_{2} \cdot \mathrm{min}^{-1} \cdot \mathrm{mg}^{-1}$ & $2.68 \pm 0.05$ & $3.57 \pm 0.22$ \\
RCR & & \\
& & \\
IMF Mitochondria & $1.16 \pm 0.11$ & $0.70 \pm 0.05^{* * *}$ \\
Mitochondrial yield, $\mathrm{mg} / \mathrm{g}$ muscle & $3055 \pm 328$ & $2567 \pm 273^{*}$ \\
Respiration State $4 \mathrm{pmol} \mathrm{O} \cdot \mathrm{min}^{-1} \cdot \mathrm{mg}^{-1}$ & $12249 \pm 1092$ & $9607 \pm 989^{* * * *}$ \\
Respiration State $3 \mathrm{pmol} \mathrm{O} \cdot \mathrm{min}^{-1} \cdot \mathrm{mg}^{-1}$ & $4.11 \pm 0.24$ & $3.66 \pm 0.25$ \\
RCR &
\end{tabular}

B

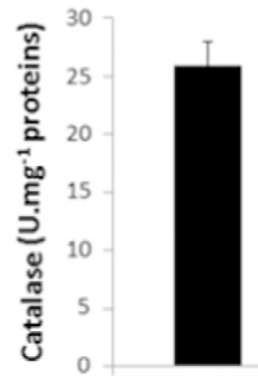

WT

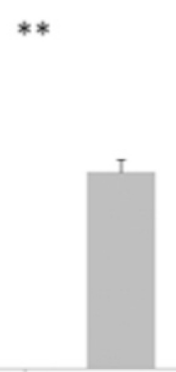

KO

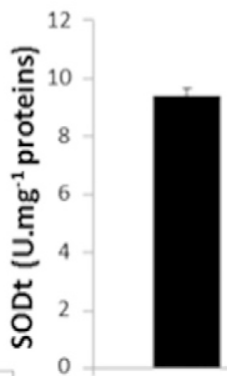

WT
***

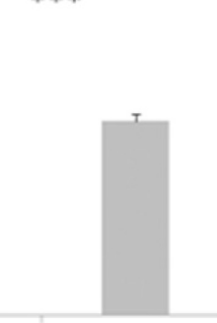

KO

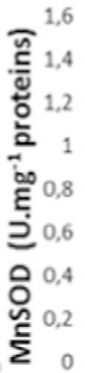

0
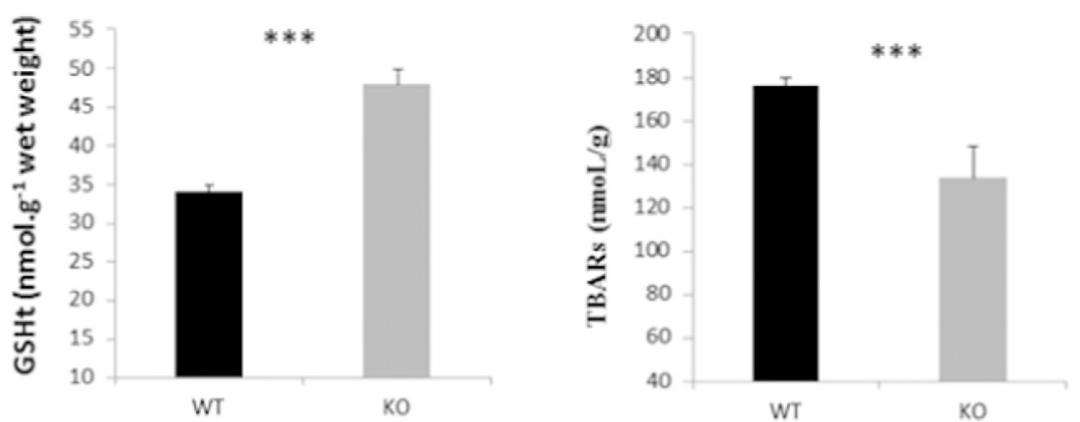

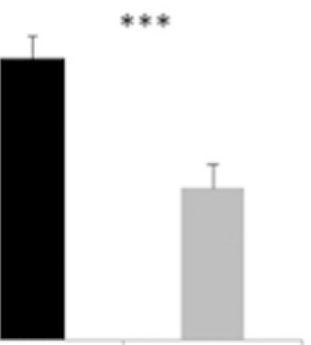

KO

Fig. 2. (A) Mitochondrial yield and respiration rates in SS and IMF subfractions in mixed muscles. Data are presented as mean \pm SE; $n=9-9$. SS, subsarcolemmal; IMF, intermyofibrillar; RCR, respiratory control ratio; ${ }^{*} p<0.05$ vs. WT, ${ }^{* *} p<0.01 \mathrm{vs}$. WT, ${ }^{* * *} p<0.001 \mathrm{vs}$. WT. (B) Gastrocnemius antioxidant enzyme activities and TBAR levels in aged WT and KO mstn mice. Data are presented as mean \pm SE; SODt, total superoxide dismutase; MnSOD, manganese superoxide dismutase; GSHt, total glutathione; TBARs, thiobarbituric acid-reactive substances. ${ }^{* *} p<0.01$ vs. WT, ${ }^{* * *} p<0.001$ vs. WT; $n=9-9$.

\subsection{Impaired running capacity is attenuated with aging in mstn KO mice}

Mstn KO mice presented a reduction in maximal aerobic velocity and running limit time compared with age-matched WT mice $\left({ }^{* * *} p<0.001\right.$;
Fig. 3). A significant negative effect of aging was observed on running limit time for both genotypes $\left(\S_{p}<0.05\right)$. Post-hoc analysis revealed that aging suppressed initial differences observed in running limit time between mstn KO and WT mice.

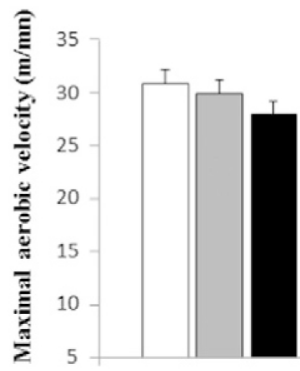

WT

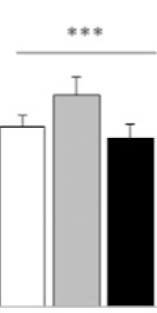

KO

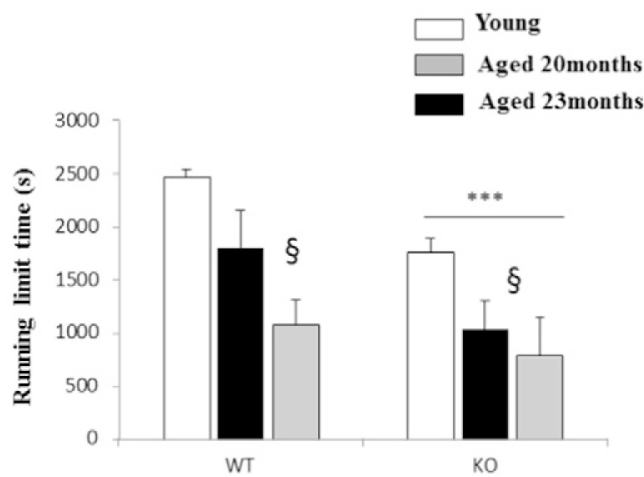

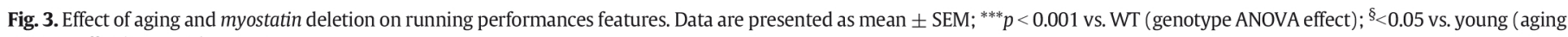
ANOVA effect); $n=9$ by groups. 

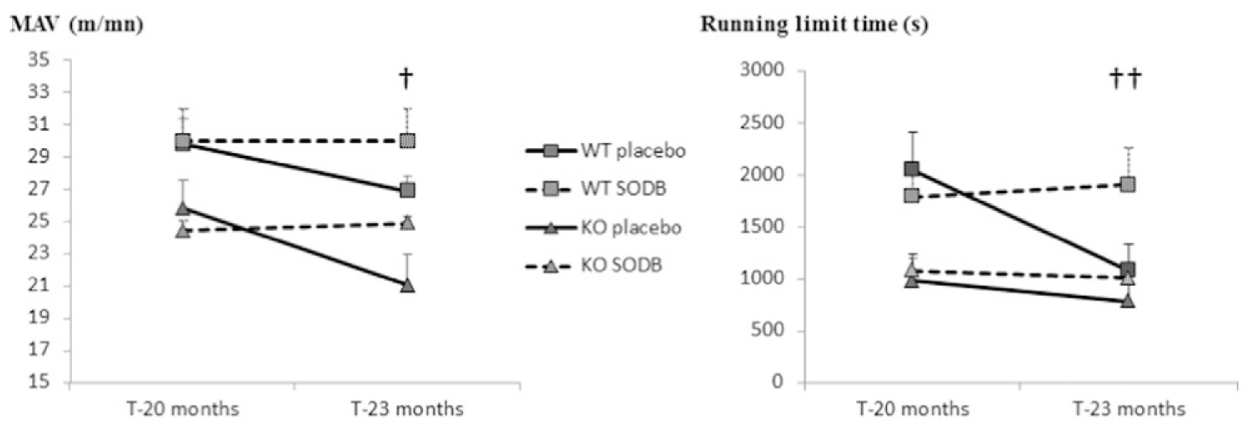

Fig. 4. Effect of 3 months of SODB treatment in aged mice groups on running outcomes. Left: mean individual groups maximal aerobic velocity values at the beginning (T-20 months) and at the end (T-23 months) of the treatment. Right: mean individual groups running limit time values at the beginning (T-20 months) and at the end (T-23 months) of the treatment. ANOVA illustrated effect treatment: ${ }^{\dagger} p<0.05$ vs. placebo; ${ }^{\dagger \dagger} p<0.01$ vs. placebo.

\subsection{Antioxidant diet attenuated negative effect of aging on running performance in aged mice}

MAV and endurance (limit time) were measured before and after the 3-month antioxidant diet in WT and KO aged mice, as illustrated by the Fig. 4. SODB diet reduced the negative effect of aging on running performance outcomes in both groups of mice supplemented. No genotype difference was observed in the response induced by the antioxidant treatment. A trend toward lesser body weight was observed in aged mice with antioxidant mix compared to placebo groups, especially in WT mice ( $p=0.06$; Table 2). Higher muscle mass for EDL was observed and when normalized by body weight, EDL, and QUAD hypertrophy index increased $(p<0.05$, Table 2$)$.

The phosphorylation of rpS6 (Ser235/236) and 4E-BP1 (Thr37/46) were measured by western blotting on EDL protein extracts. We were not able to detect any difference in rpS6 or 4EBP1 phosphorylation (activation) following SODB diet (Supplementary Fig. 2). A significant genotype effect was observed for 4EBP1 activation, whereas there was a trend for rpS6 activation. No effects of the SODB diet were measured in gastrocnemius on mitochondrial respiration rates, citrate synthase, and COX activities (Table 2).

\section{Discussion}

Current demographic trends are leading to an increased percentage of the human population living at old and very old ages (Brüssow, 2013). However, concomitant with the increase in global life expectan$\mathrm{cy}$, the number of living years with disability has been increased in most countries, consistent with the expansion of morbidity. This has implications for health planning and health-care expenditure (Salomon et al., 2012). With a growing number of aged individuals in the population, the need to prioritize healthy aging is thus increasingly recognized. Most prominent and very visible are the effects of aging on skeletal muscle. Indeed, the loss of muscle mass and increased skeletal muscle fatigue promote a sedentary lifestyle, functional and social dependence, comorbidity, and impaired quality of life (Newman et al., 2006). Increasing muscle mass through the control of mstn-mediated signaling is an attractive strategy to control muscle mass. Our present study and previous work has confirmed that mstn deletion prevent age-related skeletal muscle loss, in particular in fast-twitch muscles (Collins-Hooper et al., 2014; Mendias et al., 2015). Although maintenance of muscle mass is important for muscle function in aged individuals, muscle metabolism is also relevant to maintain muscle function.

We and others have previously shown that muscle oxidative capacity was impaired in young mstn KO animals together with decreased mitochondrial content and citrate synthase activity (Amthor et al., 2007; Ploquin et al., 2012; Baligand et al., 2010). As discussed recently, the above studies on muscle physiology emphasize that the cost to induce hypertrophy is an oxidative and mitochondrial metabolism deficit (Matsakas, 2014; Relizani et al., 2014). In particular, even when expressed relative to muscle weight, the IMF mitochondria population that provides energy for muscular contraction was depleted in young mstn KO mice and had increased basal oxygen consumption compared to wild-type littermates (Ploquin et al., 2012). In the same way, Relizani et al. (2014) demonstrated that blockade of ActRIIB signaling, via soluble receptors, downregulated porin, a crucial ADP/ATP shuttle between cytosol

Table 2

Effect of SODB diet on weight and skeletal muscle mass in aged-mice groups.

\begin{tabular}{|c|c|c|c|c|c|c|}
\hline & \multicolumn{2}{|l|}{ Aged WT } & \multicolumn{2}{|l|}{ Aged KO } & \multicolumn{2}{|c|}{ ANOVA treatment effect } \\
\hline & Placebo $(n=9)$ & $\operatorname{SODB}(n=8)$ & Placebo $(n=8)$ & SODB $(n=10)$ & Placebo $(n=17)$ & $\operatorname{SODB}(n=18)$ \\
\hline Body weight (g) & $43.3 \pm 2.3$ & $37.7 \pm 1.5$ & $42.8 \pm 0.9$ & $42.6 \pm 1.2$ & $43.1 \pm 2.3$ & $\begin{array}{l}40.1 \pm 1.1 \\
p=0.066\end{array}$ \\
\hline Quad weight (mg) & $194 \pm 7$ & $200 \pm 16$ & $291 \pm 28^{* * *}$ & $369 \pm 25^{* * *}$ & $242 \pm 18$ & $284 \pm 26$ \\
\hline Quad/BW (mg/g) & $4.5 \pm 0.2$ & $5.3 \pm 0.4$ & $6.8 \pm 0.6^{* * *}$ & $8.6 \pm 0.4^{* * *}$ & $5.7 \pm 0.4$ & $7.1 \pm 0.5^{\S}$ \\
\hline TA weight (mg) & $57 \pm 3$ & $54 \pm 1$ & $100 \pm 9^{* * *}$ & $98 \pm 7^{* * *}$ & $78.8 \pm 7.1$ & $76.3 \pm 6.5$ \\
\hline TA/BW (mg/g) & $1.3 \pm 0.06$ & $1.5 \pm 0.05$ & $2.3 \pm 0.2^{* * *}$ & $2.3 \pm 0.1^{* * *}$ & $1.8 \pm 0.2$ & $1.9 \pm 0.1$ \\
\hline EDL weight (mg) & $9.0 \pm 0.5$ & $11.1 \pm 1.5$ & $19.8 \pm 1.3^{* * *}$ & $23.3 \pm 1.6$ & $14.4 \pm 1.5$ & $17.5 \pm 1.8^{\S}$ \\
\hline EDL/BW (mg/g) & $0.21 \pm 0.01$ & $0.32 \pm 0.04$ & $0.46 \pm 0.02^{* * *}$ & $0.54 \pm 0.03^{* * * *}$ & $0.33 \pm 0.03$ & $0.43 \pm 0.04 \S \S$ \\
\hline GAS weight (mg) & $163 \pm 6$ & $156 \pm 5$ & $313 \pm 25^{* * *}$ & $286 \pm 17^{* * *}$ & $238 \pm 22$ & $221 \pm 18$ \\
\hline GAS/BW (mg/g) & $3.8 \pm 0.1$ & $4.1 \pm 0.1$ & $7.2 \pm 0.5^{* * *}$ & $6.7 \pm 0.3^{* * *}$ & $5.4 \pm 0.5$ & $5.5 \pm 0.3$ \\
\hline Soleus weight (mg) & $7.8 \pm 0.7$ & $8.1 \pm 0.6$ & $12.2 \pm 0.4^{* * *}$ & $11.4 \pm 1.1^{* * *}$ & $10.0 \pm 0.7$ & $9.8 \pm 0.8$ \\
\hline Soleus/BW (mg/g) & $0.18 \pm 0.02$ & $0.22 \pm 0.02$ & $0.29 \pm 0.01^{* * *}$ & $0.27 \pm 0.03^{* * *}$ & $0.24 \pm 0.02$ & $0.24 \pm 0.02$ \\
\hline
\end{tabular}

Data are presented as mean \pm SEM. BW, body weight; QUAD: quadriceps; TA: tibialis anterior; EDL, extensor digital longus, GAS, gastrocnemius.

Significant effect or trend to significant effect of the SODB treatment appears in bold in the table.

*** $p<0.001$ vs. WT.

$\S p<0.05$ vs. placebo.

$\S \S p<0.01$ vs. placebo. 
and mitochondrial matrix. Collectively, these studies suggest the presence of a mitochondrial metabolic perturbation, and a deficient oxidative phosphorylation process in induced or natural mstn deficiency conditions. Interestingly, we show in the current manuscript that aerobic metabolic perturbations related to mstn deletion are specific to skeletal muscle, as we did not measure any differences in liver, another tissue with high aerobic capacity, either in young or aged mstn mice. This last result highlights the importance of using skeletal muscle to study long-term metabolic adaptation in mstn deficiency conditions.

In this context, we investigated how aging, a physiological process known to affect skeletal muscle function, would impact the muscle metabolic mitochondrial and redox features in mstn-deficient mice. In the present study, we observed that only the IMF mitochondrial content is still strongly reduced in aged KO mice compared to WT, associated with a global reduction in gastrocnemius citrate synthase activity. Interestingly, this was not apparent for SS mitochondria population whose yield is elevated in aged $\mathrm{KO}$ animals. Compared to data we previously obtained in young animals (Ploquin et al., 2012), where both SS and IMF were equally reduced in KO mice, we can hypothesize that SS mitochondria population is more susceptible to aging in WT mice. In this direction, we compared RCR previously obtained in young animals (Ploquin et al., 2012) to those of the present study, and surprisingly only SS RCR value is decreased in aged WT compared to young WT mice ( 2.68 vs. 3.64, $p<0.05)$ reinforcing our previous assumption. The exploration of mitochondrial complexes activities furthermore highlights a specific alteration of mitochondrial function in WT aged animals compared to KO ones: only complex I was increased to compensate a potential aged-induced mitochondrial defect. As a result, the difference in mitochondrial function between WT and $\mathrm{KO}$ animals tends to diminish somewhat with age, confirming newly published data (Pauly et al., 2015). Similarly, aging reduced the running endurance capacity in both groups but in a gentle way in aged KO mice. On this line, the difference on running time limit between the two genotypes is attenuated. The evaluation of muscle aerobic capacity in vivo, contrary to ex vivo tests, includes both central (as cardiac output) and peripheral (related to skeletal muscle) factors. However, the likely culprit behind agerelated decline in running capacity appears to be due to peripheral factors such as the decrease in muscle mass coupled with the loss in the ability of muscle to utilize oxygen (Lakatta, 1990). We hypothesize that the prevention of age-related muscle loss reported in mstn KO mice in our present study may account for the lower age-related decline in endurance running capacity. The difference between aged wild-type and mstn KO mice could also be explained, simply because the former group of mice is aging and thus progressively acquire the metabolic alterations that occur in the mstn KO mice at young age. Together, our results suggest that with aging, the negative consequences of mstn deletion on running capacity and mitochondrial function are reduced. This is in line with newly published data from Mendias et al. on contractile properties of EDL and soleus of oldest-old Mstn $-/-$, Mstn $+/-$, and WT mice. These authors showed that the deletion of myostatin in mice protects against the aging-associated decrease in maximum skeletal muscle isometric force production without having a negative impact on specific force production (Mendias et al., 2015).

Apart from being the ATP factory of cells, mitochondria are fundamental for a myriad of functions such as redox homeostasis. Indeed, mitochondria generate intermediates for biosynthesis as well as reactive oxygen species (ROS) that serve as redox messengers in the regulation of intracellular signaling (Cheng and Ristow, 2013). Having its own antioxidant defenses, mitochondria are able to upregulate antioxidant expression following mitochondrial stress (Barbour and Turner, 2014). This is why age-dependent decline in mitochondrial pool and function can adversely affect the bioenergetic of the cells and the redox homeostasis (Cheng and Ristow, 2013). Given the mitochondrial deficit and muscle fiber glycolytic shift (Collins-Hooper et al., 2014), we would expect a decrease in overall antioxidant activities in mstn deletion conditions, especially in gastrocnemius muscle. Indeed, it is well described that SOD, catalase, and the GSH system are highly expressed in muscle fibers with high oxidative capacities (Powers et al., 2011). Consistently, the enzymatic activities of catalase and mitochondrial SOD in our aged mstn KO mice are strongly reduced compared to WT mice. Nonetheless, we noticed a marked reduction in lipid peroxidation in aged mstn-deficient muscles compared to control group. Taken together, these results raise the issue of susceptibility or resistance of mstndeficient muscle tissue to oxidative stress conditions. It underlines that mstn regulation could play a critical role in integrating redox signaling and opens up new avenues of investigation of the underlying mechanisms.

Finally, the strong decrease in MnSOD activity in KO mstn mice, associated with the deficit in muscle function in aged mice, might warrant antioxidant-enriched supplementation. Initial studies reported a beneficial effect after an oral supplementation of SODB$\mathrm{M}$ in several metabolic pathogenic models (Carillon et al., 2013, 2014a,b; Décordé et al., 2010). Indeed, previous reports showed that SODB dietary enhanced endogenous liver and adipose tissue antioxidant defense and prevented oxidative stress in young hamsters with obese phenotype (Carillon et al., 2014a) or with atherosclerosis (Décordé et al., 2010). Endogenous antioxidant defenses were also induced in the heart of spontaneously hypertensive rats after SODB supplementation (Carillon et al., 2014b). Furthermore, we ascertained that this antioxidant mix prevents in vitro $\mathrm{H}_{2} \mathrm{O}_{2}$-induced mortality of human skeletal muscle cells and did not alter the in vitro myogenic differentiation process (data not shown), a negative secondary effect that often occurs in conjunction with other antioxidant compounds (Won et al., 2012). In our present study, 12 weeks of SODBenriched diet significantly reduced the negative impact of aging on running performance outcomes in both groups of aged mice, independently of genotype. We also documented a trend to lower body weight, and secondary an increase in muscle mass hypertrophy index for two glycolytic muscles following SODB supplementation. Concerning signaling pathways related to protein synthesis, we did not detect any difference in rpS6 or 4EBP1 phosphorylation (activation) following SODB diet (data not shown). This result does not preclude any effect on protein content homeostasis, as SODB diet can also inhibit protein degradation pathways such ubiquitin proteasome system or autophagy. The antioxidant diet does not mediate improvement in running performance but prevents it decline. One part of this prevention in aged mice may be related to the preserved muscle mass, and a slightly decreased body weight that we showed in our aged treated groups. However, the absence of statistically significant and major changes in skeletal muscle biochemical assays following SODB diet underlines a potential effect of SODB on others mechanisms, such as neuromuscular transmission, central neuronal drive, or hormonal factors that account in part for the enhanced fatigue in old age (Pagala et al., 1998). For example, a recent study showed the ability of SODB to decrease adipose tissue weight and to reduce insulin resistance in obese hamsters (Carillon et al., 2014a). Taken together, these results suggest that in vivo dietary antioxidant supplementation could be a viable therapeutic option in conditions of antioxidant deficiency and/or oxidative stress, such as in aging. These results need further research to identify the mechanisms underpinning this effect.

We are aware that this study has several limitations. Mstn null mice are a genetic model of prolonged mstn deficiency. The nature of myostatin inhibition in the present study differed from the emerging therapies using for pharmacological approaches. However, post-natal mstn inhibition in adult mice causes the same metabolic changes characterizing the genetic knock-out: fiber type changes (Collins-Hooper et al., 2014), decrease in markers of oxidative metabolism (Hulmi et al., 2013; Relizani et al., 2014), or decrease in gene expression related to oxidative phosphorylation (Rahimov et al., 2011). The latter allows the study of the effects of long-term myostatin inhibition to understand 
the signalling pathways related to myostatin regulation. Moreover, myostatin inhibitory agents have been tested in aged mice and have shown favorable effects on both physical function and whole-body metabolism (White and LeBrasseur, 2014). Specifically, LeBrasseur et al. (2009) have observed that weekly injections of a neutralizing antibody to myostatin for 4 weeks significantly increased the relative weights of individual muscles by up to $17 \%$ in aged mice and improved indices of muscle performance and whole-body metabolism. On the whole, the genetic mouse model of mstn deficiency provides a complementary perspective, and this will help guide the forthcoming studies using others myostatin deficiency models: antibodies, inhibitors, and rat models. Indeed, mstn deletion models are not genetically locked and can be functionally remodeled toward oxidative metabolism by means of exercise training (Matsakas et al., 2012) or pharmacological aerobic metabolism activators (Pauly et al., 2015). Finally, Mendias et al. (2015) recently showed that heterozygous rats (Mstn $+/-$ ), which had $30 \%$ decrease in blood circulating myostatin protein, had an increase in maximal lifespan and maximum age.

To conclude, our paper conveys an improved understanding of aged mice specific metabolic changes in constitutive mstn-deficient skeletal muscle. We showed that myostatin deletion specifically impacts skeletal muscle mitochondrial function and redox status, and no other organ with high oxidative potential such as liver. Decreased mitochondrial function and oxidative markers persisted in aged mstn KO mice. However, muscle hypertrophy and the redox status related to this genotype appeared as beneficial side effects attenuating the age effect, as metabolic changes become less pronounced in comparison with WT mice. This present study opens up new areas of investigation to identify signaling pathway between mstn and redox function and supports mstn deletion as promising treatment strategy for the aged or cachectic muscle. Experiments directly inhibiting mstn by genetic or pharmacological approach should be pursued in aged animals.

\section{Funding}

This study was supported by funds from the Institut National de la Recherche Agronomique (INRA), the University of Montpellier 1, and the Bionov Company (Avignon, France). M.P. is the recipient of doctoral fellowship financed by the National Ministry of Higher Education and Research.

\section{Ethical statements}

The manuscript does not contain clinical studies or patient data. The experimental protocols of this study were handled in strict accordance with European directives on animal right (86/609/CEE) and approved by the Ethical Committee of Region Languedoc Roussillon.

Furthermore, the authors declare that they have no conflict of interest.

\section{Acknowledgments}

The authors are grateful to Sylvain Cerda, Wendy Levrat, and Christelle Bertrand-Gaday for the care of the animals used in the present study. Special thanks go to Ayesha Saleem and Pascal Goetghebeur for critical reading of the manuscript.

\section{References}

Amthor, H., Hoogaars, W.M., 2012. Interference with myostatin/ActRIIB signaling as a therapeutic strategy for Duchenne muscular dystrophy. Curr. Gene Ther. 12 (3), 245-259 (Jun).
Amthor, H., Macharia, R., Navarrete, R., Schuelke, M., Brown, S.C., Otto, A., Voit, T., Muntoni, F., Vrbóva, G., Partridge, T., et al., 2007. Lack of myostatin results in excessive muscle growth but impaired force generation. Proc. Natl. Acad. Sci. U. S. A. 104, 1835-1840.

Baligand, C., Gilson, H., Ménard, J.C., Schakman, O., Wary, C., Thissen, J.-P., Carlier, P.G., 2010. Functional assessment of skeletal muscle in intact mice lacking myostatin by concurrent NMR imaging and spectroscopy. Gene Ther. 17, 328-337.

Barbour, J.A., Turner, N., 2014. Mitochondrial stress signaling promotes cellular adaptations. Int. J. Cell Biol. 156020.

Beers Jr., R.F., Sizer, I.W., 1952. A spectrophotometric method for measuring the breakdown of hydrogen peroxide by catalase. J. Biol. Chem. 195, 133-140.

Brüssow, H., 2013. What is health? Microb. Biotechnol. 6, 341-348.

Busquets, S., Toledo, M., Orpí, M., et al., 2012. Myostatin blockage using actRIIB antagonism in mice bearing the Lewis lung carcinoma results in the improvement of muscle wasting and physical performance. J. Cachex. Sarcopenia Muscle 3, 37-43.

Carillon, J., Romain, C., Bardy, G., Fouret, G., Feillet-Coudray, C., Gaillet, S., Lacan, D., Cristol, J.P., Rouanet, J.M., 2013. Cafeteria diet induces obesity and insulin resistance associated with oxidative stress but not with inflammation: improvement by dietary supplementation with a melon superoxide dismutase. Free Radic. Biol. Med. 65, 254-261.

Carillon, J., Knabe, L., Montalban, A., Stevant, M., Keophiphath, M., Lacan, D., Cristol, J.P., Rouanet, J.M., 2014a. Curative diet supplementation with a melon superoxide dismutase reduces adipose tissue in obese hamsters by improving insulin sensitivity. Mol. Nutr. Food Res. 58, 842-850.

Carillon, J., Rugale, C., Rouanet, J.M., Cristol, J.P., Lacan, D., Jover, B., 2014b. Endogenous antioxidant defense induction by melon superoxide dismutase reduces cardiac hypertrophy in spontaneously hypertensive rats. Int. J. Food Sci. Nutr. 65, 602.

Carlberg, I., Mannervik, B., 1985. Glutathione reductase. Methods Enzymol. 113, 484-490.

Chabi, B., Ljubicic, V., Menzies, K.J., Huang, J.H., Saleem, A., Hood, D.A., 2008. Mitochondrial function and apoptotic susceptibility in aging skeletal muscle. Aging Cell 7, 2-12.

Cheng, Z., Ristow, M., 2013. Mitochondria and metabolic homeostasis. Antioxid. Redox Signal. 19, 240-242.

Cogswell, A.M., Stevens, R.J., Hood, D.A., 1993. Properties of skeletal muscle mitochondria isolated from subsarcolemmal and intermyofibrillar regions. Am. J. Physiol. 264, C383-C389.

Collins-Hooper, H., Sartori, R., Macharia, R., Visanuvimol, K., et al., 2014. Propeptide-mediated inhibition of myostatin increases muscle mass through inhibiting proteolytic pathways in aged mice. J. Gerontol. A Biol. Sci. Med. Sci. 69, 1049-1059.

Décordé, K., Ventura, E., Lacan, D., Ramos, J., Cristol, J.P., Rouanet, J.M., 2010. An SOD rich melon extract extramel prevents aortic lipids and liver steatosis in diet-induced model of atherosclerosis. Nutr. Metab. Cardiovasc. Dis. 20, 301-307.

Derbré, F., Gratas-Delamarche, A., Gómez-Cabrera, M.C., Viña, J., 2014. Inactivity-induced oxidative stress: a central role in age-related sarcopenia? Eur. J. Sport Sci. 14 (Suppl. 1), S98-108.

Fielding, R.A., Vellas, B., Evans, W.J., Bhasin, S., et al., 2011. Sarcopenia: an undiagnosed condition in older adults. J. Am. Med. Dir. Assoc. 12 (4), 249-256 (May).

Flohe, L., Gunzler, W.A., 1984. Assays of glutathione peroxidase. Methods Enzymol. 105, $114-121$.

Gallot, Y.S., Durieux, A.C., Castells, J., Desgeorges, M.M., Vernus, B., Plantureux, L., Rémond, D., Jahnke, V.E., Lefai, E., Dardevet, D., Nemoz, G., Schaeffer, L., Bonnieu, A., Freyssenet, D.G., 2014. Myostatin gene inactivation prevents skeletal muscle wasting in Cancer. Cancer Res. 74 (24), 7344-7356 (Dec 15).

Giannesini, B., Vilmen, C., Amthor, H., Bernard, M., Bendahan, D., 2013. Lack of myostatin impairs mechanical performance and ATP cost of contraction in exercising mouse gastrocnemius muscle in vivo. Am. J. Physiol. Endocrinol. Metab. 305, E33-E40.

Girgenrath, S., Song, K., Whittemore, L.A., 2005. Loss of myostatin expression alters fibertype distribution and expression of myosin heavy chain isoforms in slow- and fasttype skeletal muscle. Muscle Nerve 31, 34.

Griffith, O.W., 1980. Determination of glutathione and glutathione disulfide using glutathione reductase and 2-vinylpyridine. Anal. Biochem. 106, 207-212.

Grobet, L., Pirottin, D., Farnir, F., Poncelet, D., Royo, L.J., Brouwers, B., Christians, E., Desmecht, D., Coignoul, F., Kahn, R., Georges, M., 2003. Modulating skeletal muscle mass by postnatal, muscle-specific inactivation of the myostatin gene. Genesis 35 , 227-238.

Hulmi, J.J., Oliveira, B.M., Silvennoinen, M., Hoogaars, W.M., Pasternack, A., Kainulainen, H., Ritvos, O., 2013. Exercise restores decreased physical activity levels and increases markers of autophagy and oxidative capacity in myostatin/activin-blocked mdx mice. Am. J. Physiol. Endocrinol. Metab. 305, E171-E182.

Lakatta, E.G., 1990. Changes in cardiovascular function with aging. Eur. Heart J. 11 (Suppl. C), 22-29.

LeBrasseur, N.K., Schelhorn, T.M., Bernardo, B.L., Cosgrove, P.G., Loria, P.M., Brown, T.A., 2009. Myostatin inhibition enhances the effects of exercise on performance and metabolic outcomes in aged mice. J. Gerontol. A Biol. Sci. Med. Sci. 64 (9), 940-948 (Sep).

Lipina, C., Kendall, H., McPherron, A.C., Taylor, P.M., Hundal, H.S., 2010. Mechanisms involved in the enhancement of mammalian target of rapamycin signalling and hypertrophy in skeletal muscle of myostatin-deficient mice. FEBS Lett. 584, 2403-2408.

Marklund, S., Marklund, G., 1974. Involvement of the superoxide anion radical in the autoxidation of pyrogallol and a convenient assay for superoxide dismutase. Eur. J. Biochem. 47, 469-474.

Marzani, B., Felzani, G., Bellomo, R.G., Vecchiet, J., Marzatico, F., 2005. Human muscle aging: ROS-mediated alterations in rectus abdominis and vastus lateralis muscles. Exp. Gerontol. 40, 959-965.

Matsakas, A., 2014. Myostatin tilts the balance between skeletal muscle size, function and metabolism. Exp. Physiol. 99, 469-470.

Matsakas, A., Macharia, R., Otto, A., Elashry, M.I., Mouisel, E., et al., 2012. Exercise training attenuates the hypermuscular phenotype and restores skeletal muscle function in the myostatin null mouse. Exp. Physiol. 97 (1), 125-140. 
McPherron, A.C., 1.awler, A.M., Lee, SJ., 1977. Regulation of skeletal muscle mass in mice by a new TGF-beta superfamily member. Nature 387, 83-90.

Mendias, C.L., Bakhurin, K.1., Gumucio, J.P., Davis, C.S., Faulkner, j.A., 2015. Haploinsufficiency of myostatin protects against aging-related declines in muscle function and enhances the longevity of mice. Aging Cell. 24.

Morissette, M.R., Stricker, J.C., Rosenberg, M.A., Buranasombati, C., Levitan, E.B., Mittleman, M.A., Rosenzweig, A., 2009. Effects of myostatin deletion in aging mice. Aging Cell 8, 573-583.

Mouise), E., Relizani, K., Mille-Hamard, L, Denis, R., Hourdé, C., Agbulut, O., Patel, K, Arandel, L, Morales-Gonzalez, S., Vignaud, A., Garcia, L, Ferry, A., Luquet, S., Billat, V., Ventura-Clapier, R, Schuelke, M., Amthor, H., 2014. Myostatin is a key mediator between energy metabolism and endurance capacity of skeletal muscle. Am. j. Physiol. Regul. Integr. Camp. Physiol. 307, R444-R454.

Newman, A.B., Simonsick, E.M., Naydeck, B.L, Boudreau, R.M., et al., 2006. Association of long-distance corridor walk performance with mortality, cardiovascular disease, mobility limitation, and disability. JAMA 295, 2018-2026.

Pagala, M.K., Ravindran, K., Namba, T., 1998. Grob D Skeletal muscle fatigue and physical endurance ofyoung and old mice. Muscle Nerve 21 (12), 1729-1739 (Dec).

Pansarasa, O., Bertorelli, L, Vecchiet, j., Felzani, G., Marzatico, F, 1999. Age-dependent changes of antioxidant activities and markers of free radical damage in human skeletal muscle. Free Radie. Bio!. Med. 27, 617-622.

Pauly, M., Chabi, B., Favier, F.B., Vanterpool, F, Matecki, S., Fouret, G., Bonafos, B., Vernus, B, Feillet-Coudray, C., Coudray, C., Bonnieu, A., Ramonatxo, C., 2015. Combined strategies for maintaining skeletal muscle mass and function in aging: myostatin inactivation and AICAR-associated oxidative metabolism induction. J. Gerontol. A Bio!. Sei. Med. Sei. 70, 1077-1087.

Ploquin, C., Chabi, B., Fouret, G., Vernus, B., Feillet-Coudray, C., Coudray, C., Bonnieu, A., Ramonatxo, C., 2012. 1adk of myostatin alters intermyofibrillar mitochondria activity, unbalances redox status, and impairs tolerance ta chronic repetitive contractions in muscle. Am. J. Physiol. Endocrinol. Metab. 302, El000.

Powers, S.K., Talbert, E.E., Adhihetty, P.J, 2011. Reactive oxygen and nitrogen species as intracellular signais in skeletal muscle. j. Physiol. 589, 2129-2138.
Rahimov, F., King, O.D., Warsing, L.C., Powell, R.E., Emerson Jr., C.P., Kunkel, L.M., Wagner, K.R., 2011. Gene expression profiling of skeletal muscles treated with a soluble activin type IIB receptor. Physiol. Genomics 43 (8), 398-407 (Apr 27).

Relizani, K., Mouise), E., Giannesini, B., Hourdé, C., Patel, K., Gonzales, S.M., Jülich, K Vignaud, A., Piétri-Rouxel, F., Fortin, D., Garcia, L, Blot, S., Ritvos, O., Bendahan, D. Ferry, A., Ventura-Clapier, R, Schuelke, M., Amthor, H., 2014. Blockade of ActRIIB signaling triggers muscle fatigability and metabolic myopathy. Mol. Ther. 22, 1423.

Rodriguez,J., Vernus, B., Chelh, 1, Cassar-Malek, 1, Gabillard,J.C., Hadj, Picard, B., Bonnieu, A., 2014. Myostatin and the skeletal muscle atrophy and hypertrophy signaling pathways. Cell. Mol. Life Sei. 71 (22), 4361-4371 (Nov).

Rustin, P., Chretien, D., Bourgeron, T., Gérard, B., Rôtig, A., Saudubray, J.M., Munnich, A. 1994. Biochemical and molecular investigations in respiratory chain deficiencies. Acta lnt. J. Clin. Chem. 228, 35-51.

Salomon, J.A., Wang, H., Freeman, M.K., Vos, T., Flaxman, A.D., Lapez, A.D., Murray, C.j. 2012. Healthy life expectancy a systematic analysis for the Global Burden Disease Study 2010. l.ancet 380, 2144-2162.

Sriram, S., Subramanian, S., Sathiakumar, D., Salerno, M.S., McFarlane, C.D., Kambadur, R. Sharma, M., 2011. Modulation of reactive oxygen species in skeletal muscle by myostatin is mediated through NF-KB. Aging Cell 10, 931-948.

Wharton, D.C., Tzagoloff, A., Ronald, Estabrook W., 1967. Cytochrome oxidase from beef heart mitochondria. Methods in Enzymology. Academic, New York, NY, pp. 245-250.

White, T.A., LeBrasseur, N.K., 2014. Myostatin and sarcopenia: opportunities and challenges-a mini-review. Gerontology 60 (4), 289-293.

Won, H., Lim, S., Jang, M., Kim, Y., et al., 2012. Peroxiredoxin-2 upregulated by NF-KB at tenuates oxidative stress during the differentiation of muscle-derived $\mathrm{C} 2 \mathrm{Cl} 2$ celis Antioxid. Redox Signal. 16, 245-261.

Zhou, j.Y., Prognon, P., 2006. Raw material enzymatic activity determination: a specific case for validation and comparison of analytical methods: the example of SOD. J. Pharm. Biomed. Anal. 40, 1143-1148. 